\title{
Portal Vein
}

National Cancer Institute

\section{Source}

National Cancer Institute. Portal Vein. NCI Thesaurus. Code C33343.

A short thick trunk vein that transports blood containing the absorbed products of digestion from the intestine directly to the liver. 